\title{
FUTURE SKILLS AND HIGHER EDUCATION “FUTURE SKILL READINESS"
}

\author{
Ulf-Daniel Ehlers, Baden-Wurttemberg Cooperative State University, Germany
}

\section{Introduction}

The discourse on the future of higher education is already an old one. Higher education Institutions are used to it and are slow in turning around which makes them stable and enduring organisations. In a way institutions and society are benefitting from their internal protection mechanisms which goes along with the status of autonomy and independence they are granted in democratic societies. However, in recent times it becomes clear that we are approaching a peak point in the "race between technology and education" as the Dutch Nobel Prize winner Jan Tinbergen called it about four decades ago (Tinbergen, 1975). One popular theory to explain the rising trend in inequality was first put forward by the Dutch Nobel Prize winner in Economics Jan Tinbergen over four decades ago. He characterised wage inequality as being the outcome of a "race between education and technology". In this theory, technology increases the relative demands for more skilled labour while education increases the relative supplies of such labour. Thus, rising inequality implies that technology is winning this race. It is characterized by technology, global and globally networked societies, institutions and individuals and education systems as a whole will have to make the next move in this race - and evolve in the light of to these developments, change their mode of working and evaluate their objectives. This is especially true for higher education amongst educational institutions, as the last autonomous and self-governed institutions in the education sphere. One important piece in this puzzle is the question of direction - change in which direction? What are the new skills which are needed for our societies to be sustainable and our organisations to be fit for the changed environments?

In this article we are presenting parts of a 2019 international Delphi survey about future skills in higher education (more in Ehlers, 2019, in print). The research is based on a multi-part research project called "Next Skills" in which we have been conducting research to shed light on the demand for specific skills which we refer to as "future skills" (more on www.nextskills.org). As has been demonstrated by other studies, too (see for instance Deming, 2017; Noweski, Scheer, Büttner, von Thienen, Erdmann, \& Meinel, 2012; OECD, 2017), research in this area is of vital importance as future graduates need to adapt to an increasingly changing and complexity-gaining world that demands agility and "innovation in action". To address this field systematically, we pursued the question which skills are necessary for future employees and which skills are perceived as necessary to shape the future of society in a sustainable way. Other questions which we focus on in the project but will not 
present in this paper are how learning will look like on the future and how higher education institutions will have to change.

We approached these questions from a systems-ecological understanding of changing systems in society and their interconnectedness (Woodside et al., 2006), as well as from an education science point of view on competences (following the action oriented competence concept defined by Erpenbeck, 2010). Two studies have been conducted prior to the Delphi survey. The first project started in June 2015. In this we identified and analysed competence concepts in more than 120 German organizations. These had been identified on basis of submissions to an award scheme rewarding advanced concepts of skill, learning and competence frameworks within organizations. To take part in this award, organizations were asked to share their competence models and trainings offered to promote their employees' skill formation. Winners were then invited to participate in a qualitative interview study. Through an expert screening and analysis, we were able to identify main dimensions of action competence within the overall concepts submitted by the participating organizations. According to the expert's opinion, about 20 organizations in the sample proved to have very advanced, developed, and elaborated conceptions and documented approaches for competence development with their employees and advanced learning architectures. Within these documents, experts also found evidence of skill and competence descriptions, which are seen as important and essential for individuals' and organizations' performances in future markets and activities. For the second research project, the research team chose 17 organizations from this group of advanced, future organizations in order to conduct further research into finding dimensions and structures of future skills. To gain further insights into the specific skill set, organizational approaches to promote them as well as for the purpose of identifying drivers leading to the changed skill demand, we took a qualitative approach and conducted 17 indepth interviews with representatives from a sample of those organizations, resulting in more than 700 minutes of interview material addressing the above questions. Based on the material, two researchers coded all interviews independently using the inductive coding technique (Thomas, 2006) and the software MAX QDA (VERBI Software, 2017). After coding, passages lacking unanimity were discussed among the researchers to gain inter-operator reliability in coding. As a result, we have obtained a set of future skills, insights into dimensions of change in organizations through digital and networked global collaboration processes and have specified a number of scenarios of future higher education. These results were taken as the basis for the international Delphi survey on future skill - future learning and future higher education. The international Delphi study focused on validating and elaborating the qualitative constructs gained through the interview study. In this paper we are presenting the result on one particular part of the study, the 16 future skills derived from our analysis, validated and elaborated through the international Delphi experts, as well as their opinion about higher education "future skill-readiness".

\section{Methodology}

The survey design has been carefully crafted on basis of previous experiences: Firstly, the international expert panel is described below (their professional as well as national 
backgrounds, and their fields of interest). Secondly, an overview on the themes, questions and survey logic of the two rounds of the Delphi survey will be provided.

\section{The panel}

We invited 53 international experts from different organizations and institutions. They worked within higher education institutions, as researchers in the field of pedagogy, networks concerned with learning and skill formation topics, the digitalization of higher education or within NGOs (more details in Ehlers \& Kellermann, 2019). It was important to us, to consider the perspectives of both, representatives from higher education institutions as well as from consultants and practitioners from the economy. Further, we paid close attention to the fact that within the two sub-samples, people occupying different positions were included in order to allow for a maximum of differentiation and plurality of opinions on the topics surrounding the future of learning, skills and higher education, and avoid blind spots. 49 international experts participated in round 1, 46 experts in round 2, representing about 17 different countries (Australia, Austria, Belgium, Canada, France, Germany, China, Italy, Lithuania, Netherlands, New Zealand, Norway, Portugal, Spain, Sweden, Switzerland, and the United Kingdom).

\section{Delphi method}

The Delphi survey had two rounds, the second administered four weeks after the first. Both rounds were mainly focusing on asking experts to clarify concepts, definitions, terminology and rating importance (round 1) and of time to adoption in the field of future skills (round 2). The question logic can be seen in the figure representing the different thematic parts and showing how the two rounds build on each other. An important focus was put on participants' views of the abilities, the processes, the strategies, skills and competences which employees needed and will need in the future in order to cope and productively deal, as well as further develop the increasingly faster changing organizational reality. The experts provided ratings and opinions through qualitative comments which were analysed and resulted into improved and enhanced formulation of statements.

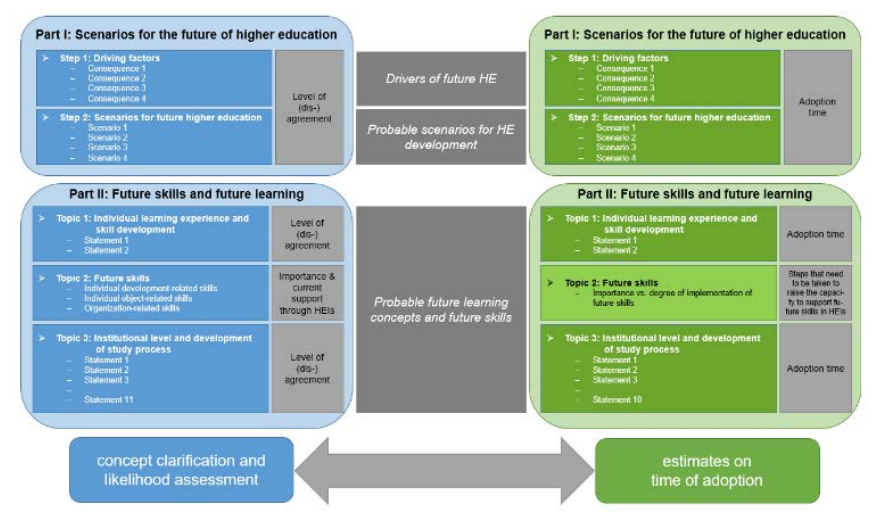

Figure 1. Delphi survey structure 


\section{Future Skills - and Higher Education Institutions' "Future Skill Readiness"}

\section{The Future Skills Approach - A Theoretical Model}

Data for the future skill model were triangulated regarding methodology, data sources and theories used to reconstruct skills. The analysis of data resulted in a reconstruction of factors which are underlying future skill demands and reveals insights into the form and importance of learning in todays and future professional work environments of advanced "future" organizations. It allows a reconstruction of those specific individual abilities and skills which will - in the future - will be necessary to deal with challenges in professional future work environments.

A first important issue is to note that "skill" is a term which is always expressing a relation. Only in a relation, a skill becomes meaningful. A communication skill for example as such is not meaningful but communication in a skillful way of somebody in relation to something is. Using this insight, we were able to identify an inherent structure within the list of future skills, allowing for classification of such "future skill relations" into field of skill profiles which each has distinct relations. They can be classified according to the target of their relation weather it is related to a subject (individual to itself) - object (individual to a certain task) - or environment (individual to social environment). Thus three dimensions allow to allocate skills according to their relation to subject - object - world. Important: All three dimensions are interrelated, and influence each other. We are introducing this threefold distinction (see Figure 2) because any kind of skill, ability or action can either be an expression to shape (a) an individual's relation to itself in past present or future (time dimension), (b) an individuals' relation to a certain thing or object (object dimension), or (c) an individuals' relation to somebody else or a group in the word (social dimension).

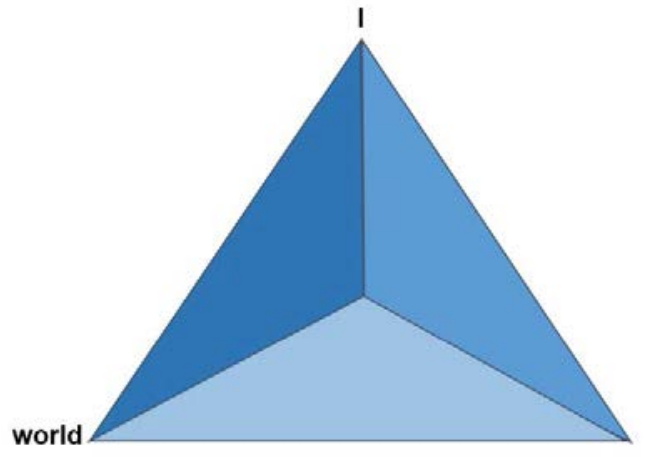

Figure 2. Three-fold distinction of future skills

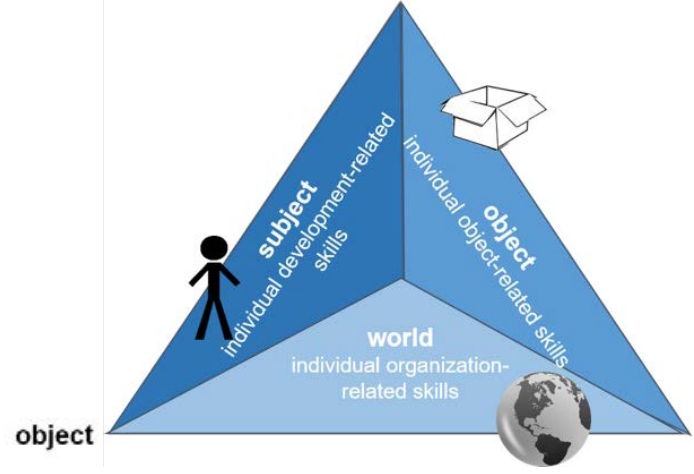

This threefold distinction is rooted deep into philosophy of education (e.g. Dewey in his essay Knowing the Known) but recently goes back to Meder (2007, also Roth 1971), who is presenting a foundational, constitutive structure for education as a threefold relation. Our future skill concept is based on three different moments of theoretical reflection:

- $\quad$ skills are understood as "competences" as defined by Erpenbeck (2010), emphasizing that competences are dispositions to act in complex unknown future contexts; 
- skills are viewed as relational concepts which can be described within the three dimensions of the structural view of education;

- future skills are viewed as a reaction to shifts which take place within the different parts of the theoretical framework, and can be described through the set of 16 future skill profiles.

The threefold concept which we suggest in our research as a theoretical basis allows to root the future skill discourse in education theory. This gives more direction and precision to skill terminology and allow to describe more precisely what we refer to as future skills instead of just listing terms in an additive fashion. In all of the three dimensions' shifts are going on. The interview data reveal a clear change in nature of what is demanded in the future in comparison to the past and in parts the present.

- Shift 1 - Subject related individual skills: Whereas in the past individuals could rely on following requirements, the future will demand more self-organization instead.

- Shift 2 - Object related individual skills: Whereas in the past individuals could rely on applying knowledge, methods and tools, the future will demand original creative development of new knowledge, methods and tools.

- Shift 3 - World/ organizational related skills: Whereas in the past organisations were organized and management according to clear structures, the future will demand fluid, enabling, agile cultures.

Figure 3 shows that shifts take place in all three dimensions (called "areas of action" in Figure 3). In addition, data reveal shifts in different fields as well by emphasizing the greater importance of individuals' responsibility for their own development, as well as competence management and autonomous navigation through an ever faster changing environment. Whereas in the past external (organizational) structures were a scaffold which provided guidance and orientation to individuals, such external structure and scaffolding will be decreasing in the future. Thus, individuals will have a stronger role to be navigators of themselves (in Figure 2 referred to as "relational structure"). And, finally, the components which skills are made up through (e.g. knowledge, skills and attitudes) are subject to shift as well. In our concept of skills, a skill is made up of four dimensions: knowledge, an (instrumental) application ability, a design-ability, and critical reflection-ability. Within these four parts of a skill, a greater emphasis will be on design-ability and critical reflection-ability can be perceived for future skills. Figure 2 shows that knowledge and application of knowledge will be such foundational elements which will, in the future, not be sufficient for successful performance. Much more importance was given to the two elements "designability" and "criticism/ reflection-ability" for future performance (called "skills dimensions" in Figure 2). 


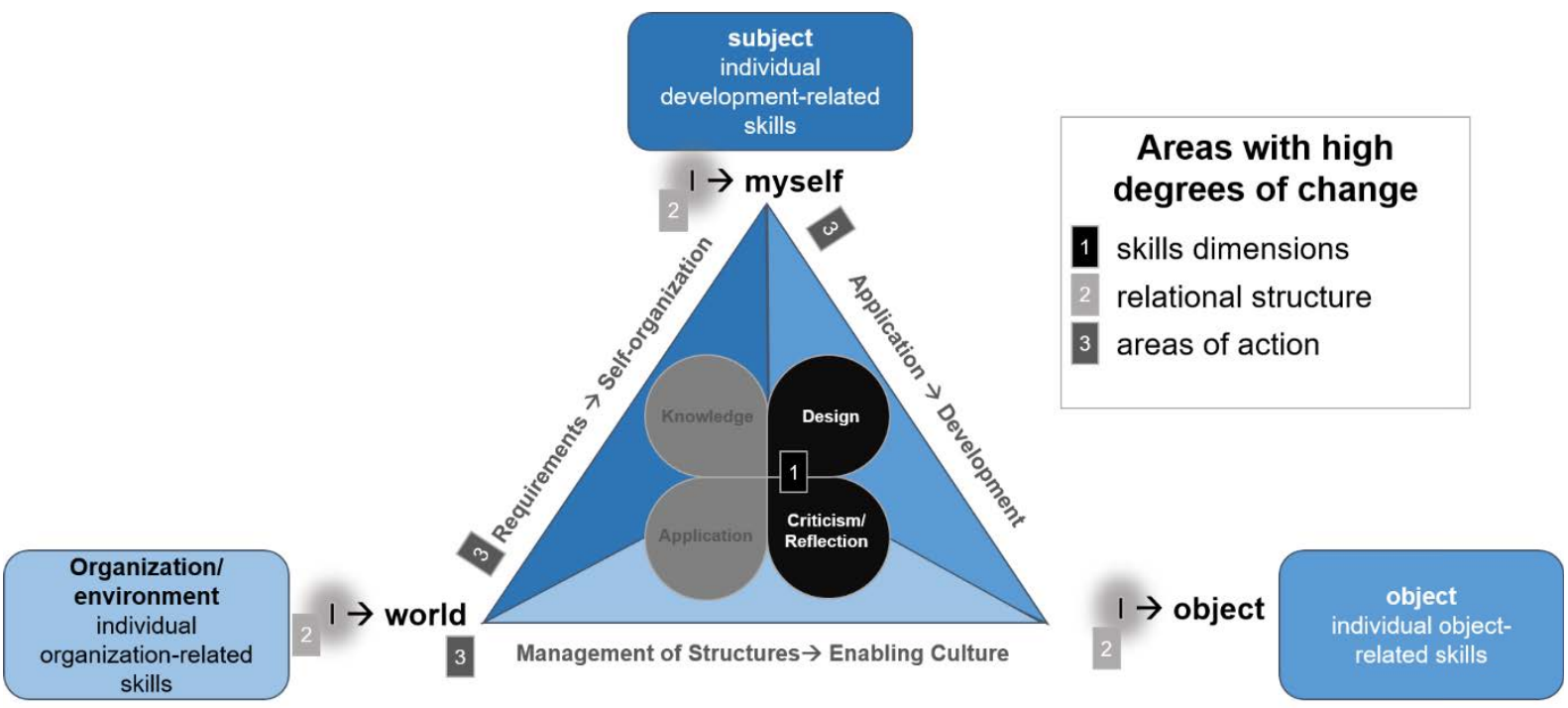

Figure 3. Combing the structural education model with the competency model to explain future skills

All three dimensions interact with each other and are not sole expressions of isolated skill domains. Subjective aspects influence outlook on objective aspects as well as social aspects impact subjective and objective aspects. The presented future skill model is thus going beyond a static model of listing a set of defined skills. It is secondly going far beyond digital or technical skills which will no doubt be important but represent just one ingredient for future skills. Their true values lie in the personal development of dispositions to act self-organized in a defined domain.

In summary, the future skill model is capable of describing the wide array of future skills in a clearly structured and well-described set of dimensions:

- The first future skill dimension is the subjective dimension of futures skills profiles. It is relating to an individuals' subjective, personal abilities to learn, adapt and develop in order to improve their opportunities to productively participate in the workforce of tomorrow, actively shape the future working environment and involve themselves into forming societies to cope with future challenges. It contains seven future skill profiles.

- The second future skill dimension is relating to an individual's ability to act selforganized in relation to an object, a task or a certain subject matter related issue. It is emphasizing a new approach which is rooted into the current understanding of knowledge but is suggestion to take knowledge several steps up the ladder, connect it to motivation, values and purpose and impregnate it with the disposition to act selforganized in the knowledge domain in question. It is not just a quest for more knowledge but for dealing with knowledge in a different way which is resulting into professionalism and not into knowledge expertise.

- The third future skill dimension is relating to an individual's ability to act selforganized in relation to its social environment, the society and organizational environment. It is emphasizing the individuals' dual role as the curator of its social portfolio of membership in several organizational spheres and at the same time having 
the role of rethinking organizational spaces and creating organizational structures anew to make it future proof. It contains an array of five skill profiles.

\section{The 16 Future Skills Profiles}

Two main orientations for future skills have been defined through the study and the experts' judgement, they represent the main foundation for the future skill concept. They point to the essence of the future skills context: (a) constant adoption through learning and (b) uncertainty as inherent trait of professional contexts of the future. Specifically, the second aspect is constitutional for skills, as skill is defined as dispositions to act in future unknown contexts - rather than as reproduceable knowledge. In the Delphi survey, both statements received high levels of agreement, supported through qualitative commenting of experts, and are also seen as relevant today or within the next 5 years by the majority of experts. $89.2 \%$ of the respondents indicated agreement with our first proposition that the greatest challenge students would need to be prepared for through HEIs would be the constant need for "adaption through learning" in constantly changing future work environments $(M=4.17$, $\left.S D=0.81, \quad A_{\text {Adaption(strongly agree) }}=37.0 \%, A_{\text {Adaption(agree) }}=52.2 \%\right) . \quad A_{\text {Adaption(strongly agree) }}$ indexes the percentage of respondents, who strongly agreed with the statement, whereas $A_{\text {Adaption(agree) }}$ shows the percentage of the sample that expressed agreement.

Table 1: $\quad$ List of future skills

\begin{tabular}{ll}
\hline Subject & Object \\
\hline $\begin{array}{l}\text { Autonomy: capacity to make an } \\
\text { informed, uncoerced decision } \\
\text { and act accordingly }\end{array}$ & $\begin{array}{l}\text { Agility: ability to orient } \\
\text { oneself in fast } \\
\text { changing contexts, } \\
\text { constantly changing } \\
\text { objects }\end{array}$ \\
$\begin{array}{l}\text { Self-initiative: individual ability } \\
\text { Creativity: to be able to } \\
\text { approach to work goals and } \\
\text { dasks }\end{array}$ & $\begin{array}{l}\text { deal with task in a new, } \\
\text { unforeseen way }\end{array}$
\end{tabular}
Social

Sense making: ability to identify with and make sense of given organizational rules and values for one's own life and work

Future mindset: ability to productively develop an organizations' context, continuously learn and develop one's skills and to be open for new and unknown challenges within a given organizational context

Self-management: ability to lead and regulate oneself to decide in a self-responsible way

Need/ motivation for achievement: individual's desire for significant accomplishment, mastering of skills, control, or high standards

Personal agility: positive attitude, resilience and openness to changes, being comfortable in ambiguous and changing situations

\section{Tolerance for} ambiguity: ability to deal with uncertainty and in different roles Digital literacy: ability to utilize digital technology in a creative way for learning, working, collaboration Ability to reflect: ability to critically analyse made experiences and learn for future contexts
Cooperation skills: ability to cooperate in teams and have social and intercultural skills

Communication competence: ability to actively create dialogue, achieve consensus and criticize 
Autonomous learning

competence: ability to

continuously adapt through

learning, know learning

methods, evaluate own

progress, ability to learn

motivated

Self-efficacy: one's own

conviction to be able to act

successfully on a given task

Figure 4 shows the skill profiles which are described in Table 1. As mentioned above it is important to note that each 'skill profile' contains a number of subskills which are viewed by the participants of the interview study as important within this skill profile (Ehlers, 2019, in print). The second statement suggested that the ability to successfully deal with uncertainty would become the most important skill in future work environments. The experts' opinion was largely overall in agreement with this position $\left(M=3.73, S D=1.10, A_{\text {Uncertaintysstrongly }}\right.$ agree) $\left.=26.7 \%, A_{\text {Uncertainty(agree) }}=40.0 \%\right)$. $A_{\text {Uncertainty(strongly agree) }}$ indexes the percentage of respondents, who strongly agreed with the statement, whereas $A_{\text {Uncertainty (agree) }}$ shows the percentage of the sample that expressed agreement. The majority of elaborative comments stressed that experts perceived this skill to be or to become increasingly important, accompanying other future skills in their rise to importance.

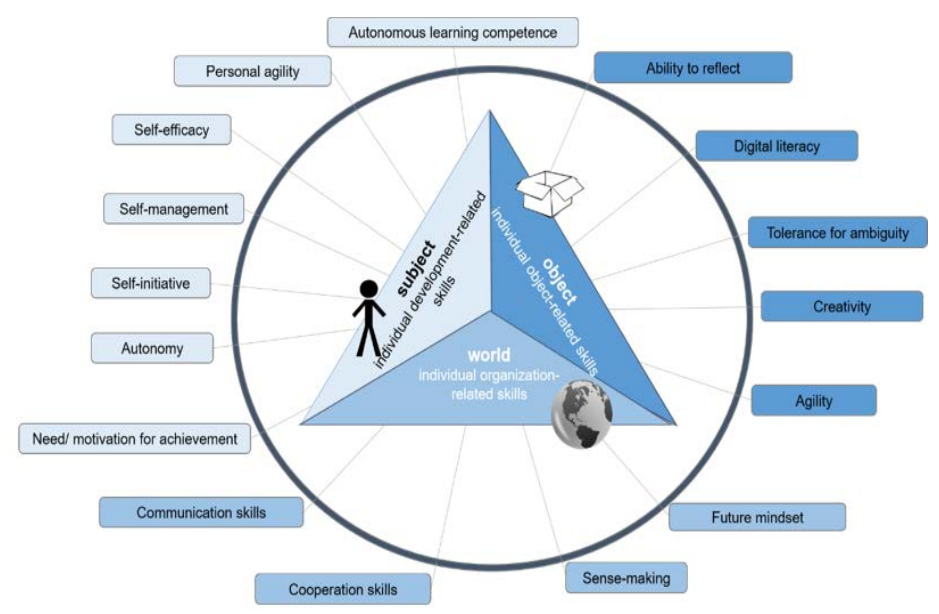

Figure 4. Delphi survey structure

The future skill profiles were validated and rated through Delphi experts - both on their importance, as well as on experts' opinion about higher education readiness to adopt those future skills into their mission. Both variables were assessed on a five-point Likert-scale, whereby importance ranged from 5 - very important to 1 - not important and support from 5 - very good to 1 - very poor. To gain an overview on the discrepancy between skill's importance and its respective level of support in higher education, we calculated the delta, subtracting the mean support from the mean importance.

All individual development-related Future Skills are perceived as important, with autonomy being rated as very important $(M=4.53, S D=0.62)$. Autonomous learning competence 
$(M=4.48, S D=0.69)$ and self-management $(M=4.46, S D=0.72)$ occupied the second and third most important positions. Contrary to that the degree of implementation in higher education, expressing the evaluation of exerts how well HEI are equipped to support the development of these skills is rated. The delta between both values has been calculated. It shows that the largest discrepancy is perceived for the autonomous learning competence $(\Delta=1.83)$ and autonomy $(\Delta=1.81)$ - two of the skills that earlier had been rated among the most important.

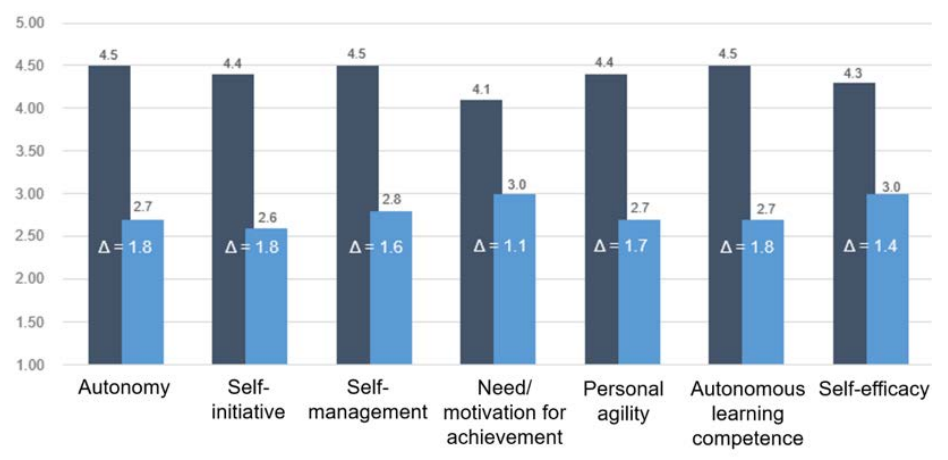

Figure 5. Subject and individual development related skills: Importance (dark blue bars) versus current degree of higher education support (light blue bars) $(\mathrm{N}=46)$

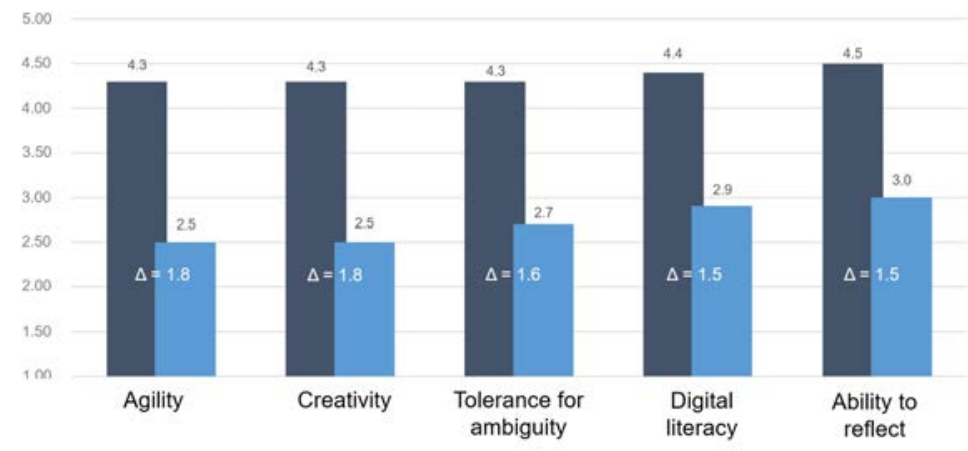

Figure 6. Object-related skills (Instrumental skills):

Importance (dark blue bars) versus current degree of higher education support (light blue bars) $($ NImportance $=44$, NSupport $=45)$

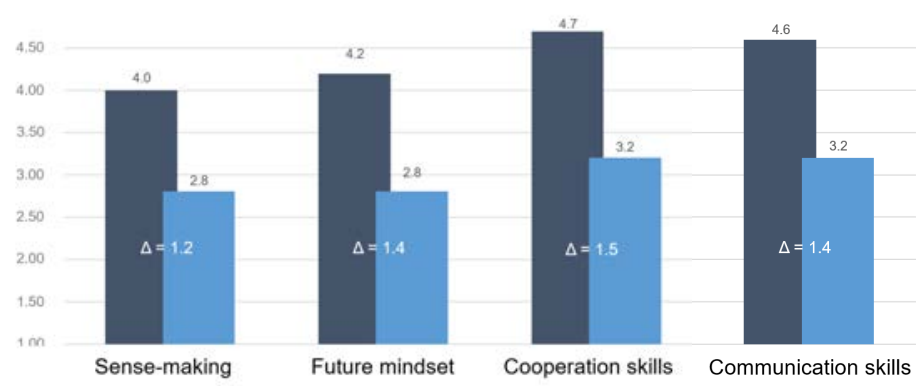

Figure 7. Organization-related skills:

Importance (dark blue bars) versus current degree of higher education support (light blue bars) $(\mathrm{N}=45)$ 
Object related skills are skills which are relying on individual dispositions to act in unknown future environments but where the object of action is not the individual itself but a certain object which needs to be acted upon - e.g. a certain task.

The expert sample rated all skills to be important, except for the ability to reflect, which was even voted to be very important $(M=4.50, S D=0.67)$. Furthermore, the data reveals that the ability to reflect is one of the currently best-supported skills in HEIs compared to the other object-related skills. Least support apparently exists for agility and creativity skills $(M=2.53$, $S D=0.87 ; M=2.52, S D=0.85$ ), leading to the highest perceived discrepancy between agility skills' importance and their current support through HEIs.

Individual organization related skills are those skills which are needed to act in organizational and social environments. Action is self-organized and understood as disposition. In this section all skills are perceived of as important, whereby cooperation and communication skills are even rated to be very important $(M=4.59 S D=0.67 ; M=4.67, S D=0.67)$. Moreover, all skills were rated to be acceptably support within HEIs, whereby the two most important skills (cooperation and communication skills) were deemed to be the best supported across all Future Skills $(M=4.59 S D=0.67 ; M=4.67, S D=0.67)$

\section{Conclusion}

With regards to future skills we can conclude:

- Future skills can be analysed and described as a set of profiles, each containing an array of skill definitions covering future skill demands.

- These skills can be referred to as future skills and can generally be described through two cornerstone characteristics: a strong, transversal and well-developed ability of selforganization, which is mutually supported through a high-articulated supposition to act under conditions of uncertainty. Proficiency in any profession in the future will entail these two traits.

- Future skills can be described within a model, which is structured into three dimensions: subjective - individual development-related, objective - task and subject matter-oriented, social - organizational and environment-related. All three dimensions interact with each other and are not sole expressions of isolated skill domains. Subjective aspects influence the outlook on objective aspects as well as social aspects impact subjective and objective aspects.

- The future skill approach presented here is going beyond a static model of listing a set of defined skills. It is going beyond digital or technical skills which will - no doubt carry high importance for the future workforce but represent just one ingredient. The specific value of the presented future skill approach lies within the combination of focusing on the development of dispositions to act in a self-organized manner in the respectively described domain with a defined array of skills. 


\section{References}

Bronfenbrenner, U. (1977). Toward an experimental ecology of human development. American Psychologist, 32(7), 513-531.

Brown, B. B. (1968). Delphi process: A methodology used for the elicitation of opinions of experts. (No. RAND-P-3925). Santa Monica, CA.: RAND Corp.

Deloitte (2018). Reconstructing Jobs: Creating good jobs in the age of artificial intelligence. Retrieved from https://www2.deloitte.com/content/dam/insights/us/ articles/AU308_Reconstructing-jobs/DI_Reconstructing-jobs.pdf

Ehlers, U. D. (2019, in print). Future Skills - Zukunft des Lernens, Zukunft der Hochschule. Gütersloh.

Ellebracht, H., Lenz, G., Osterhold, G., \& Schäfer, H. (2009). Systemische Organisations-und Unternehmensberatung. Springer Fachmedien.

Erpenbeck, J. (2010). Kompetenzen. Eine begriffliche Klärung. In H. Volker (Ed.), Grundstrukturen menschlicher Kompetenzen. Praxiserprobte Konzepte und Instrumente. Münster.

Helmer, O. (1967). Analysis of the future: The Delphi method (No. RAND-P-3558). Santa Monica, CA.: RAND Corp.

Linstone, H. A., \& Turoff, M. (1975). The Delphi method: Techniques and applications. London: Addison-Wesley.

Meder, N. (2007). Der Lernprozess als performante Korrelation von Einzelnem und kultureller Welt. Eine bildungstheoretische Explikation des Begriffs. Spektrum Freizeit, 07(I\&II), 119-135.

OECD (2017). Future of Work and Skills. 2nd Meeting of the G20 Employment Working Group. Hamburg. Retrieved from https://www.oecd.org/els/emp/wcms_556984.pdf

OECD (2017). OECD Digital Economy Outlook 2017. Paris: OECD Publishing. https://doi.org/10.1787/9789264276284-en

OECD (2017). OECD Employment Outlook 2017. Paris: OECD Publishing. https://doi.org/10.1787/empl_outlook-2017-en

OECD (2018). “A Brave New World: Technology and Education”. Trends Shaping Education Spotlights, No. 15. Retrieved from http://www.oecd.org/education/ceri/Spotlight-15-ABrave- New-WorldTechnology-and-Education.pdf

OECD (2018). The Future of Education and Skills. Education 2030. Position Paper. Retrieved online from https://www.oecd.org/education/2030/E2030\%20Position\%20

Paper\%20(05.04.2018).pdf

OECD (2019). Trends Shaping Education 2019. OECD Publishing. Paris. https://doi.org/10.1787/trends_edu-2019-en 
Roth, H. (1971). Pädagogische Anthropologie. Band II. Entwicklung und Erziehung. Grundlagen einer Entwicklungspädagogik. Hannover: Schroedel.

Thomas, D. R. (2006). A general inductive approach for analyzing qualitative evaluation data. American Journal of Evaluation, 27(2), 237-246.

Tinbergen, J. (1975). Income Distribution: Analysis and Policies. Amsterdam: North-Holland.

VERBI Software (2017). MAXQDA 2018 [computer software]. Berlin, Germany: VERBI Software. Retrieved from https://www.maxqda.com

Woodside, A. G., Caldwell, M., \& Spurr, R. (2006). Advancing Ecological Systems Theory in Lifestyle, Leisure, and Travel Research. Journal of Travel Research, 44(3), 259-272. doi:10.1177/0047287505282945

World Economic Forum (2018). Towards a Reskilling Revolution: A Future of Jobs for All. 